\title{
Phonological memory in bilinguals and monolinguals
}

\author{
Jeewon Yoo • Margarita Kaushanskaya
}

Published online: 21 August 2012

(C) Psychonomic Society, Inc. 2012

\begin{abstract}
In the present study, we examined the effects of lexical-semantic knowledge and of difficulty level on phonological memory performance by monolingual adult English speakers and bilingual adult Korean-English speakers. The monolingual English speakers were more proficient in English than the bilingual speakers. All participants were tested on a range of phonological memory tasks in English. We manipulated the degree to which the phonological memory tasks involved lexical-semantic knowledge of English (word-span task, digit-span task, and nonword repetition task), as well as the difficulty level of the tasks. Results revealed that on the word-span task (highest level of lexical-semantic knowledge), monolinguals outperformed bilinguals at the easier levels of the task but bilinguals outperformed monolinguals at the more difficult levels of the task. For the digit-span and nonword repetition tasks, monolinguals outperformed bilinguals at the easier levels of the tasks, but the differences between the two groups vanished with the increase in the difficulty levels. Together, these results suggest that proficiency-based differences between monolingual and bilingual phonological memory performance depend on the degree to which the tasks rely on lexical-semantic knowledge and the difficulty level of the task.
\end{abstract}

Keywords Bilingualism · Short term memory $\cdot$ Working memory

J. Yoo $(\bowtie) \cdot$ M. Kaushanskaya

Department of Communicative Disorders,

University of Wisconsin-Madison,

1975 Willow Drive,

Madison, WI 53706, USA

e-mail: yoo9@wisc.edu

\section{Phonological memory in bilinguals and monolinguals}

Phonological memory is defined as the ability to maintain verbal information in memory for a brief period of time. This skill is imperative for performing complex linguistic tasks in both the native (L1) and the second (L2) language (e.g., Christoffels \& de Groot, 2005), including auditory language comprehension (e.g., Smith, Mann, \& Shankweiler, 1986) and written language processing (e.g., Daneman \& Carpenter, 1980; Swanson \& Berninger, 1995). The storage capacity of the phonological memory system is limited, and human beings can maintain only a few items in memory at any one time. However, there is remarkable variability in the population, with some individuals demonstrating high phonological memory capacity and others demonstrating low phonological memory capacity. What determines the phonological memory capacity? One factor in particular - the structural knowledge of one's language - has been linked to the efficiency with which the phonological memory system encodes information (e.g., Cheung, 1996; Harrington \& Sawyer, 1992; Windsor, Kohnert, Lobitz, \& Pham, 2010).

The relationship between language knowledge and phonological memory is obviated by studies that examine phonological memory in bilinguals (e.g., Cheung, 1996; Gathercole \& Baddeley, 1990; Masoura \& Gahtercole, 1999; Michas \& Henry, 1994; Service, 1992; Thorn \& Gathercole, 1999). It is well documented, for example, that in bilinguals whose language proficiency in the L2 is lower than the L1 proficiency of the monolingual peers, phonological memory performance is also lower than in the monolinguals (e.g., Messer, Leseman, Boom, \& Mayo, 2010; Windsor et al., 2010). However, it is unknown whether the degree to which a bilingual's phonological memory performance in the L2 deviates from a monolingual's phonological memory performance depends on the extent to which the phonological memory tasks involve the lexical-semantic knowledge of the target language and on the 
difficulty level of the task. Yet the structural knowledge of one's language and the difficulty level of the task form the basis for the modern theories of short-term memory (STM; e.g., Cowan, 1988, 1999, 2001). Therefore, the goal of the present study was to compare phonological memory abilities in bilinguals' L2 and monolinguals' L1 on a range of phonological memory tasks that varied in the degree to which they engaged lexical-semantic knowledge. We also manipulated difficulty levels of the tasks in order to examine whether increased pressure on the phonological memory system would modulate discrepancies between bilingual and monolingual phonological memory performance. Knowing how precisely lower proficiency in the L2 affects phonological memory performance on different phonological memory tasks would enable us to formulate precise models of the relationship between long-term linguistic knowledge and the STM system. Furthermore, manipulating the difficulty level of the phonological memory tasks would allow us to examine the interactions between language-specific knowledge and cognitive resources within the phonological memory system and to propose the mechanisms behind the effects of bilingualism on memory.

\section{Phonological memory system and long-term knowledge}

Although different memory models disagree about the structure and the modularity of the various memory systems, all models of STM posit that the STM system interacts with the long-term memory (LTM) system. For example, Baddeley's model of working memory (WM) separates short-term storage in the WM system from the knowledge stored in the LTM (e.g., Baddeley, 2001) but presupposes that the two systems interact during memory tasks through the episodic buffer (e.g., Baddeley, 2000). Cowan (1988, 1999, 2001) suggests that the STM is a subset of the LTM. According to Cowan's embedded-processes WM model, STM is part of the contents of the LTM. In other words, STM is information stored in the LTM that is activated above some threshold for a particular task. Within this temporarily activated information, some information becomes the focus of attention, while other information that is not in the band of focused attention becomes inactive. Similarly, Engle, Kane, and Tuholski (1999) argued that WM consists of a subset of activated LTM information units and specified the relationship between WM and LTM simply as "WM = STM (activated portion of LTM) + controlled attention" (p. 126).

There is empirical evidence suggesting that long-term knowledge affects the STM performance. For example, participants are more successful at remembering words than nonwords (e.g., Gathercole, Frankish, Pickering, \& Peaker, 1999; Hulme, Maughgan, \& Brown, 1991) and at remembering highfrequency words than low-frequency words (Hulme et al., 1997). Similarly, participants are more successful at remembering nonwords of high phonotactic probability than nonwords of low phonotactic probability (Gathercole et al., 1999) and nonwords that are more wordlike than nonwords that are less wordlike (Gathercole, 1995). These long-term knowledge effects on STM performance have been explained in terms of redintegration. Specifically, it is proposed that the incomplete or partially lost representations in the temporary storage (STM) can be redintegrated (that is, repaired or restored) by the permanent representations in the LTM (Gathercole et al., 1999; Schweickert, 1993; Thorn, Gathercole, \& Frankish, 2005). As a result, immediate recall tasks using words and nonwords are supported by long-term knowledge with lexical-semantic representations likely activated for real words and with phonological, sublexical representations likely activated for nonwords. Therefore, while it is possible to vary the degree to which long-term linguistic knowledge influences phonological memory performance, it is, in fact, difficult to design a pure phonological memory task that would not involve any activation of long-term linguistic knowledge (e.g., Hulme et al., 1991).

Perhaps the most compelling evidence for the close association between linguistic knowledge and phonological memory comes from studies comparing phonological memory performance in the L1 versus the L2. In bilingual adults, the linguistic knowledge in the L2 typically falls below the linguistic performance of the monolingual native speakers (e.g., Bialystok \& Feng, 2009; Roberts, Garcia, Destochers, \& Hernandez, 2002), even when bilinguals are fairly proficient in their L2 (e.g., Portocarrero, Burright, \& Donovick, 2007). In a number of studies, it has been demonstrated that bilinguals perform better on the phonological memory tasks in their native and more proficient language than in their second and less proficient language (Cheung, 1996; Gathercole \& Baddeley, 1990; Harrington \& Sawyer, 1992; Masoura \& Gahtercole, 1999; Michas \& Henry, 1994; Service, 1992; Thorn \& Gathercole, 1999). Similarly, monolinguals tend to outperform bilinguals on phonological memory tasks when the task is administered in the monolinguals' L1 and the bilinguals' L2 (e.g., Messer et al., 2010; Windsor et al., 2010). Lower phonological memory performance in bilinguals, as compared with monolinguals, reflects the discrepancies in linguistic knowledge between the two groups. However, it is unknown whether bilingual/monolingual differences in performance on phonological memory tasks hold for different types of phonological memory tasks involving different degrees of linguistic knowledge.

In the present study, we capitalized on the common mechanisms outlined by the different models of STM where the information stored in the LTM can constrain the ability to retain information in the STM. That is, we hypothesized that the ability to encode information in STM would be constrained by the degree to which the LTM could be involved in the encoding process. We then examined whether the extent to which the to-be-remembered information taps the long-term linguistic knowledge influenced performance on phonological 
memory tasks by monolinguals performing the tasks in their $\mathrm{L} 1$ and by bilinguals performing the tasks in their L2. To that end, we contrasted three phonological memory tasks that differed with respect to the linguistic knowledge they activated: a word-span task (high degree of lexical-semantic knowledge), a digit-span task (low degree of lexical-semantic knowledge), and a nonword repetition task (sublexical phonological knowledge only). The use of the three tasks tests the degree to which linguistic knowledge modulates phonological memory performance. We manipulated the difficulty level of each task in line with the models of STM that posit that the increase in the difficulty level of the memory task is associated with an increased reliance on domain-general attentional mechanisms.

Phonological memory system and task difficulty

Classic theories of WM distinguish the STM and the WM through the involvement of the central executive (e.g., Baddeley, 1986, 2000). These classic models posit that STM tasks index the storage capacity of the phonological memory, while WM tasks index the storage capacity of the phonological memory and the ability to engage in cognitive processing. WM performance, but not STM performance, therefore relies on the function of the central executive- the component of Baddeley's WM model that focuses and switches attention during memory tasks (e.g., Baddeley, 2000, 2003; Baddeley \& Hitch, 1974). Thus, STM tasks include simple span tasks, such as a word span task, a nonword repetition (NWR) task, or a digit-span task, while WM tasks include complex span tasks, such as a reading span task or an operation span task. The interactive models of WM (e.g., Cowan, 1999; Majerus, Heiligenstein, Gautherot, Poncelet, \& Van der Linden, 2009; Unsworth \& Engle, 2006), however, suggest that the distinction between the STM and the WM tasks lies not in the presence of a secondary cognitive processing task, but in the difficulty level of the primary task.

In the interactive models of WM, the ability to focus attention on the relevant information relies on the central executive system, which is responsible for voluntary, effortdemanding processes (e.g., Cowan, 2001; Engle et al., 1999). Cowan (1999) argued that STM capacity is constrained by the strength with which information is activated in the LTM. Within this temporarily activated information, some information becomes the focus of attention. Because the ability to focus attention is capacity limited, the more difficult the task, the higher the demand for attention. Therefore, simple (STM) tasks and complex (WM) tasks both tap the storage and the executive control abilities, but the two types of tasks differ in the degree to which they rely on the central executive (Cantor, Engle, \& Hamilton, 1991; Engle, Tuholski, Laughlin, \& Conway, 1999; Kail \& Hall, 2001; Kane et al., 2004; Unsworth \& Engle, 2006). STM tasks are easier and, therefore, rely on the central executive less than do WM tasks.
A number of studies support the relationship between STM and WM performance (e.g., Kail \& Hall, 2001; Unsworth \& Engle, 2006). For example, Unsworth and Engle (2006) examined performance on verbal complex span tasks (i.e., reading span and operation span) and simple span tasks (i.e., word span and letter span) as a function of list length. Results revealed that the simple span performance at the long list lengths and performance on all the complex span list lengths shared a large amount of common variance, suggesting that the more difficult simple span tasks and complex span tasks tapped the same mechanisms. Therefore, increasing task difficulty is an effective way to manipulate the involvement of the central executive in memory performance. In the present study, we manipulated the difficulty levels of the verbal memory tasks in order to examine whether the involvement of the central executive would modulate verbal memory performance differently in bilinguals versus monolinguals. We hypothesized that the increase in the difficulty level of the phonological memory task would be associated with an increase in the degree to which the central executive (or controlled attention) would be involved in task performance. In hypothesizing that increased reliance on the central executive would shift the patterns of difference between bilingual and monolingual phonological memory performance, we were motivated by previous works suggesting that bilingualism may facilitate domain-general controlled-attention mechanisms.

\section{Controlled attention in monolinguals and bilinguals}

It is well documented that life-long bilingualism influences the cognitive system both functionally and structurally. A number of studies have reported that bilinguals outperform monolinguals on nonverbal executive function tasks (e.g., Bialystock \& Shapero, 2005; Mezzacappa, 2004; Zelazo, Frye, \& Rapus, 1996). Bilinguals are especially likely to outperform monolinguals on tasks that require inhibitory control and selective attention to environmental stimuli (e.g., Bialystok, 1999; Bialystok, Craik, Klein, \& Viswanathan, 2004; Bialystok \& Feng, 2009). One common explanation for these bilingual advantages is that constant practice inhibiting cross-linguistic competition translates into improved performance on nonlinguistic tasks that require inhibition (Blumenfeld \& Marian, 2011; Bialystok, Craik, \& Ryan, 2006; Costa, Hernandez, \& Sebastián-Gallés, 2008). Because WM capacity has been shown to be related to performance on a number of attention task involving the central executive system, including Stroop (Kane \& Engle, 2003), antisaccade (Kane, Bleckley, Conway, \& Engle, 2001), and flanker (Heitz \& Engle, 2007) tasks, it is possible that bilingualism also influences WM performance.

In the nonlinguistic domain, a positive effect of bilingualism on WM has been demonstrated by Bialystok et al. (2004). Specifically, Bialystok et al. (2004) manipulated both congruency (indexing inhibitory control) and the number of visual 
stimuli (indexing WM capacity) on the Simon task. The results revealed bilinguals' advantages over monolinguals on both measures. Bialystok et al. (2004) suggested that bilinguals' better performance on inhibition trials and that on WM trials were both rooted in the central executive. However, this finding is at odds with studies of verbal memory performance in bilinguals, where consistently lower performance was observed in bilingual than in monolingual speakers, especially when bilinguals were tested in their L2 (e.g., Messer et al., 2010; Windsor et al., 2010). In the present study, we examined whether the differences between bilinguals and monolinguals on the verbal memory tasks would be conditioned by the difficulty level of the task. We expected that bilingualism would facilitate the efficient use of central executive (i.e., domain-general attention resources) and, therefore, the size of the difference on verbal memory tasks between bilinguals and monolinguals would be reduced with the increase in the difficulty levels of the tasks.

\section{Present study}

In the present study, we examined how bilinguals and monolinguals performed on phonological memory tasks in a target language that was bilinguals' L2 and monolinguals' L1. First, we examined whether lower levels of linguistic knowledge would reduce bilinguals' performance on targetlanguage phonological memory tasks, as compared with monolinguals. We were especially interested in whether bilingual/monolingual differences in performance would depend on the degree to which a phonological memory task involved the knowledge of semantic and lexical information in the target language. To that end, we contrasted a wordspan task (highest lexical-semantic knowledge), a digit-span task, and a NWR task (lowest lexical-semantic knowledge).

The word-span task requires participants to recall real words, either independently of order or in the same order as that in which they occurred, immediately after hearing or reading a list of words (e.g., Shah \& Miyake, 1996). Successful performance on the word-span task depends crucially on one's semantic and lexical knowledge of the language in which the task is administered (Engle, Nations, \& Cantor, 1990; Harrington \& Sawyer, 1992; Poirier \& SaintAubin, 1995; Watkins \& Watkins, 1977). The digit-span task requires participants to recall sequences of digits. Because access to digit names becomes highly automatic through frequent use (e.g., Gathercole \& Adams, 1993) and because the semantic value of digits is entirely transparent and clearly specified, unlike that of other words in the lexicon (e.g., Damian, 2004; Dehaene \& Mehler, 1992), the influence of prior language knowledge on phonological memory is lower for the digit-span span task than for the word-span task (e.g., Harrington \& Sawyer, 1992). Finally, the NWR task requires participants to listen to nonsense words and to repeat them back as accurately as possible (e.g., Gathercole et al., 1999; Gathercole, Willis, Emslie, \& Baddeley, 1991). Unlike the word-span and the digit-span tasks, the NWR task is assumed to mostly involve sublexical knowledge (i.e., knowledge of fine-grained phonological representations), rather than lexical or semantic knowledge (e.g., Baddeley, Gathercole, \& Papagno, 1998; Edwards, Beckman, \& Munson, 2004; Gathercole \& Baddeley, 1989; Munson, 2001).

The differences in the degree to which semantic and lexical long-term knowledge is involved in the word-span versus the digit-span versus the nonword repetition tasks enable us to ask how these discrepancies are reflected in bilingual versus monolingual phonological memory performance. Given that in our study, bilinguals' L2 was less proficient than monolinguals' L1, it was reasonable to hypothesize that bilinguals' lower lexical and semantic target-language skills would be particularly disadvantageous to performing the phonological memory task that relied on lexical and semantic knowledge the most (i.e., the word-span task). However, the converse was also possible; that is, it may be that not being able to take advantage of lexical-semantic knowledge (even when the levels of that knowledge are fairly low) would place bilinguals at a disadvantage. The result would be that monolinguals would outperform bilinguals on tasks that involve the lowest levels of lexical and semantic knowledge (i.e., the NWR task).

Second, we examined whether the involvement of the central executive system in the memory tasks would influence the patterns of differences between bilinguals and monolinguals. To manipulate the involvement of the central executive system in phonological memory performance, we systematically varied the difficulty levels of the three phonological memory tasks. Specifically, we manipulated the syllable and the list length on the word-span task and the complexity of the NWR and the digit-span tasks as a way to increase the difficulty level of the task and, thus, the involvement of the central executive in the memory process. Increase in word length (e.g., Archibald \& Gahtercole, 2006; Baddelely, Tomson, \& Buchanan, 1975; Girbau \& Schwartz, 2007; LaPointe \& Engle, 1990; Lovatt, Avons, \& Masterson, 2000) and in list length (e.g., Baddeley et al., 1975; Hulme, Thomson, Muir, \& Lawrence, 1984) have both been linked to increased difficulty levels of the memory task. Similarly, an imposition of a secondary processing task has been shown to increase the difficulty levels of the memory task (e.g., Conklin, Curtis, Katsanis, \& Iacono, 2000; Daneman \& Capenter, 1980; Engle et al., 1999; Just \& Carpenter, 1992; Turner \& Engle, 1989). We hypothesized that the differences in performance on the phonological memory tasks between bilinguals and monolinguals would be reduced as the demands on central executive increased. This hypothesis was based on previous studies showing that bilingualism may facilitate executive functions, which appear to be closely linked with WM capacity. What is most interesting, 
however, is the interplay between the particular task and the difficulty-level manipulation in bilinguals versus monolinguals. The crucial question asked in the present study was whether the difficulty-level manipulation would influence bilingual versus monolingual performance differently for tasks that involved different degrees of linguistic knowledge.

\section{Method}

\section{Participants}

Twenty-four Korean-English bilinguals participated in the study. Of those, three outliers (participants who got the perfect score on the nonverbal IQ test) were excluded from the analyses. The average age of the remaining 21 KoreanEnglish bilinguals was 28.43 years. All participants spoke Korean as their L1 and had acquired English as an L2 during early teen years, with a mean acquisition age of 10.38 years $(S D=3.83)$. Participants had spent an average of 5.5 years in an English-speaking country and indicated that Korean was their dominant language. Participants also rated their L2 proficiency levels including speaking, understanding, and reading on a Likert scale where 0 stood for no knowledge and 10 stood for native-like knowledge. Detailed information regarding participants' L2 proficiency and experience can be found in Table 1.

Twenty-four English-speaking monolinguals participated in this study. Of those, one outlier (participant who scored more than 1 standard deviation below the mean IQ for the sample) was omitted from the analyses. The average age of the remaining 23 monolingual participants was 24.58 years. Monolingual participants also rated their English proficiency levels on a Likert scale. The two groups differed in their selfreported English proficiency, with monolinguals reporting higher English proficiency levels for speaking, understanding, and reading than bilinguals. These self-reported differences were confirmed by standardized measures of English vocabulary knowledge. English monolingual participants outperformed the bilingual participants on both the receptive vocabulary measure (Peabody Picture Vocabulary Test-III; Dunn \& Dunn, 1997) and the expressive vocabulary measure (Expressive Vocabulary Test; William, 1997). The lower English proficiency in bilinguals, as compared with monolinguals, was expected and, thus, was part of the overall design. The groups did not differ in age or in their nonverbal intelligence as measured by the Visual Matrixes subtest (indexing nonverbal IQ) of the Kaufman Brief Intelligence Test-2 (KBIT2; Kaufman \& Kaufman, 2004).

\section{Stimuli}

All the stimuli for the three phonological memory tasks were in English - the L1 for the monolinguals and the L2 for the bilinguals.

\section{Word-span task}

A free-recall word-span task was designed, where participants heard lists of words and were asked to retrieve them regardless of order. One hundred fifty English nouns were selected for the word-span task. The nouns chosen were one, two, and three syllables in length. In each syllable set, nouns were grouped into lists of 5, 10, 15, and 20 words (see Appendix 1). Across each syllable set and across each list set, nouns were matched on frequency (on the basis of the Brysbaert \& New, 2009, database), and concreteness (MRC Psycholinguistic Database) (see Table 2). The nouns were also matched in phonotactic probability (calculated according to Vitevitch \& Luce, 2004) and in phonological neighborhood size (calculated according to Marian, Bartolotti, Chabal, \& Shook, 2012) across lists. The exception to this

Table 1 Demographic characteristics of Korean-English bilinguals and English monolinguals

\begin{tabular}{llll}
\hline & $\begin{array}{l}\text { Bilinguals } \\
\text { Mean }(S D)\end{array}$ & $\begin{array}{l}\text { Monolinguals } \\
\text { Mean }(S D)\end{array}$ & $F$ value \\
\hline Age & $28.43(5.49)$ & $24.58(6.56)$ & $F(1,28)=2.49$ \\
Years of education & $19.06(3.92)$ & $16.03(2.24)$ & $F(1,28)=9.36^{*}$ \\
Daily exposure to English (\%) & $59.76(12.79)$ & $93.68(7.62)$ & $F(1,28)=62.77^{*}$ \\
Self-rated English speaking proficiency (zero-to-ten scale) & $6.29(1.74)$ & $9.42(0.69)$ & $F(1,28)=34.21^{*}$ \\
Self-rated English understanding proficiency (0-to-10 scale) & $6.57(1.70)$ & $9.37(0.96)$ & $F(1,28)=26.99^{*}$ \\
Self-rated English reading proficiency (0-to-10 scale) & $7.48(1.47)$ & $9.32(0.89)$ & $F(1,28)=17.68^{*}$ \\
Receptive Vocabulary Standard Score (PPVT-III) & $88.67(10.13)$ & $116.58(10.22)$ & $F(1,28)=48.12^{*}$ \\
Expressive Vocabulary Standard Score (EVT) & $97.20(12.44)$ & $117(13.18)$ & $F(1,28)=19.58^{*}$ \\
Nonverbal IQ Standard Score (KBIT-II) & $112.50(10.81)$ & $106.71(11.81)$ & $F(1,28)=0.52$ \\
\hline
\end{tabular}

* Significant differences between groups are asterisked at the $p<.05$ (adjusted for multiple comparisons). The degrees of freedom reflect the fact that some participants did not answer some questions on the LEAP-Q and were, thus, eliminated from the multivariate analyses of variance 
Table 2 Concreteness and frequency of word stimuli in word-span task

\begin{tabular}{llll}
\hline Syllable length & List length & $\begin{array}{l}\text { CNC } \\
\text { Mean }(S D)\end{array}$ & $\begin{array}{l}\text { FREQ } \\
\text { Mean }(S D)\end{array}$ \\
\hline 1 & 5 & $569.40(32.04)$ & $33.48(26.26)$ \\
& 10 & $564.70(58.10)$ & $51.37(68.13)$ \\
& 15 & $559.67(48.76)$ & $39.31(57.23)$ \\
& 20 & $571.40(42.11)$ & $25.79(25.31)$ \\
& 5 & $571.80(9.36)$ & $25.86(20.23)$ \\
& 10 & $552.70(39.35)$ & $34.50(64.97)$ \\
& 15 & $562.33(49.55)$ & $20.78(22.82)$ \\
& 20 & $558.35(54.80)$ & $26.56(31.94)$ \\
& 5 & $588.40(23.94)$ & $12.01(5.72)$ \\
& 10 & $546.70(45.84)$ & $15.85(12.32)$ \\
& 15 & $544.20(61.06)$ & $20.22(29.26)$ \\
& 20 & $558.65(39.59)$ & $26.24(24.10)$ \\
\hline
\end{tabular}

Note. Across syllable lengths and list lengths, there were no significant differences in concreteness (CNC) and in frequency (FRE), all $p \mathrm{~s}>.05$

was neighborhood size of one-syllable words across the four lists (see Table 3). However, the nouns were not matched between syllable lengths across lists, because an increase in syllable length invariably results in decreased average phonotactic probability and neighborhood density of the words. Phonotactic probability was larger for one-syllable words than for two- and three-syllable words but did not differ between two- and three-syllable words. Phonological neighborhood size was larger for one-syllable words than for two-syllable words and for two-syllable words than for three-syllable words (see Table 3).

\section{Digit-span tasks}

The Memory for Digits subtest of the Comprehensive Test of Phonological Processing (Wagner, Torgesen, \& Rashotte, 1999) was used to measure participants' forward digit-span skills. The task started with two-digit sequences and increased to eight-digit sequences incrementally, with three trials per sequence length. The Numbers Reversed subtest of the Woodcock-Johnson III Tests of Cognitive Abilities (WJIII COG/NU; Woodcock, McGrew, \& Mather, 2005) was used to measure participants' backward digit-span skills. The task started with two-digit sequences and increased to eight-digit sequences. There were five trials for two-digit and three-digit sequences and four trials per sequence length for sequences of four to eight digits.

\section{NWR tasks}

One hundred forty-four English nonwords were selected from an established corpus of nonword stimuli (Gupta et al., 2004). Of these, 48 were two-syllable nonwords, 48 were foursyllable nonwords, and 48 were six-syllable nonwords (see Appendix 2). The stimuli were split, so that there were three pairs of 16 two-syllable nonwords, three pairs of 16 foursyllable nonwords, and three pairs of 16 six-syllable nonwords. Each member of the triplet was presented in the STM task, the unimodal WM task, or the cross-modal WM task. We used a simple NWR task to measure STM capacity and two complex NWR tasks to measure WM capacity. For the WM tasks, one set of nonwords was combined with an animacy judgment task (unimodal WM task), and the other set of nonwords was combined with a visual search task (cross-modal WM task).

Table 3 Phonotactic probability and neighborhood size of word stimuli in word-span task

\begin{tabular}{|c|c|c|c|c|c|c|}
\hline & & \multicolumn{4}{|c|}{ List length } & \multirow[t]{2}{*}{ Comparison across list lengths } \\
\hline & & 5 & 10 & 15 & 20 & \\
\hline \multicolumn{7}{|c|}{ Phonotactic probability } \\
\hline \multicolumn{7}{|c|}{ Mean $(S D)$} \\
\hline \multirow[t]{3}{*}{ Syllable length } & 1 & $.21(.02)$ & $.17(.06)$ & $.17(.06)$ & $.15(.70)$ & \multirow{3}{*}{$F(3,146)=1.84, p=.14$} \\
\hline & 2 & $.14(.03)$ & $.13(.03)$ & $.15(.04)$ & $.12(.05)$ & \\
\hline & 3 & $.16(.03)$ & $.14(.06)$ & $.12(.04)$ & $.13(.03)$ & \\
\hline \multicolumn{2}{|c|}{ Comparison across syllable lengths } & \multicolumn{4}{|c|}{$F(2,147)=6.84, p<.001^{*}$} & \\
\hline \multicolumn{7}{|c|}{ Neighborhood size } \\
\hline \multicolumn{7}{|c|}{ Mean $(S D)$} \\
\hline \multirow[t]{3}{*}{ Syllable length } & 1 & $30.40(15.95)$ & $29.50(12.74)$ & $17.33(10.69)$ & $18.40(9.83)$ & \multirow[t]{3}{*}{$F(3,136)=1.43, p=.24$} \\
\hline & 2 & $6.50(1.29)$ & $7.30(6.18)$ & $4.54(4.82)$ & $5.79(7.48)$ & \\
\hline & 3 & $1.25(0.50)$ & $1.30(0.48)$ & $1.67(0.78)$ & $1.50(0.79)$ & \\
\hline \multicolumn{2}{|c|}{ Comparison across syllable lengths } & \multicolumn{4}{|c|}{$F(2,137)=79.83, p<.001 *$} & \\
\hline
\end{tabular}

Note. Across list lengths, there were no significant differences in phonotactic probability and neighborhood size, all $p \mathrm{~s}>.05$. Across syllable lengths, there were significant differences in phonotactic probability and neighborhood size (i.e., increased syllable length $\rightarrow$ reduced phonotactic probability/neighborhood size) 
Across the three tasks, nonwords were matched on acoustic duration in milliseconds. We also matched average phonotactic probability and neighborhood density of the nonwords across the three tasks (see Table 4). However, the nonwords of different length differed in phonotactic probability and neighborhood density. Phonotactic probability was larger for two-syllable nonwords than for four-syllable and six-syllable nonwords but did not differ between four-syllable and sixsyllable nonwords. Neighborhood density was larger for twosyllable nonwords than for four-syllable and six-syllable nonwords but did not differ between four-syllable and six-syllable nonwords (see Table 4).

In the STM NWR task, participants heard a nonword and repeated it as accurately as possible. In the unimodal WM task, participants heard the nonword, followed by an auditory presentation of a noun. Participants decided whether the noun was animate or inanimate and then repeated the nonword as accurately as possible. The 25 animate and 23 inanimate nouns selected for the unimodal WM task were matched on frequency, concreteness, and familiarity. In the cross-modal WM task, participants heard the nonword, followed by a presentation of a visual grid that contained variously configured "L" shapes (e.g., some were rotated, and some flipped). Participants decided whether there was an upright canonical " $L$ " shape on the grid and then repeated the nonwords as accurately as possible. Half of the visual-search displays contained the canonical "L" shape, while the other half did not (randomized across trials).

The English nonwords and nouns (for both the unimodal WM task and the word-span task) were recorded by a female native speaker of English. All recordings were made in the soundproof booth at $20 \mathrm{KHz}$ sampling rate, and saved as .wav files. These .wav files were then normalized using
Praat to $70-\mathrm{dB}$ amplitude in order to ensure comparable acoustic parameters across conditions.

Procedure

The order in which the tasks were administered was randomized for each participant.

\section{Word-span task}

Participants listened to lists of English words and were asked to recall as many words in the list as possible, regardless of order. They started with one-syllable words in lists of $5,10,15$, and 20 words each, followed by two-syllable words and three-syllable words. The time interval between words was $500 \mathrm{~ms}$, and the presentation of words in the set was randomized within each set and for each participant. Participants' productions were recorded and coded off-line.

\section{Digit-span tasks}

For the forward digit-span task, participants listened to strings of digits and were asked to recall the digits in the same order as that in which they heard them. For the backward digit-span task, participants listened to strings of digits and were asked to recall the digits in the reverse order from the one in which they had heard them. Responses were coded online.

\section{NWR tasks}

The order of the three NWR tasks was counterbalanced across participants. Two-syllable nonwords were always

Table 4 Phonotactic probability and neighborhood size of nonword stimuli in NWR tasks

\begin{tabular}{|c|c|c|c|c|c|}
\hline & & \multicolumn{3}{|c|}{ Task } & \multirow[t]{2}{*}{ Comparison across tasks } \\
\hline & & simple NWR & complex NWR-animacy & complex NWR-visual & \\
\hline \multicolumn{6}{|c|}{ Phonotactic probability } \\
\hline \multicolumn{6}{|c|}{ Mean $(S D)$} \\
\hline \multirow[t]{3}{*}{ Syllable length } & 2 & $.13(.03)$ & $.13(.02)$ & $.12(.02)$ & \multirow{3}{*}{$F(2,141)=0.01, p=.99$} \\
\hline & 4 & $.10(.02)$ & $.09(.02)$ & $.10(.02)$ & \\
\hline & 6 & $.10(.03)$ & $.10(.02)$ & $.10(.03)$ & \\
\hline \multicolumn{2}{|c|}{ Comparison across syllables } & \multicolumn{3}{|c|}{$F(2,141)=21.17, p<.001 *$} & \\
\hline \multirow{2}{*}{\multicolumn{6}{|c|}{$\begin{array}{c}\text { Neighborhood size } \\
\text { Mean }(S D)\end{array}$}} \\
\hline & & & & & \\
\hline \multirow[t]{3}{*}{ Syllable length } & 2 & $0.25(0.58)$ & $0.25(0.45)$ & $0.44(1.03)$ & \multirow[t]{3}{*}{$F(2,141)=0.32, p=.73$} \\
\hline & 4 & $0.00(0.00)$ & $0.00(0.00)$ & $0.00(0.00)$ & \\
\hline & 6 & $0.00(0.00)$ & $0.00(0.00)$ & $0.00(0.00)$ & \\
\hline \multicolumn{2}{|c|}{ Comparison across syllables } & \multicolumn{3}{|c|}{$F(2,141)=9.06, p<.001 *$} & \\
\hline
\end{tabular}

Note. Across tasks, there were no significant differences in phonotactic probability and neighborhood size, all $p \mathrm{~s}>.05$. Across syllable lengths, there were significant differences in phonotactic probability and neighborhood size (i.e., increased syllable length $\rightarrow$ reduced phonotactic probability/neighborhood size) 
presented first, followed by four-syllable and six-syllable nonwords. In all three NWR tasks (STM, unimodal WM, and cross-modal WM), the time between the presentation of the nonword and the cue to repeat it was set to $4,000 \mathrm{~ms}$. The picture of a microphone on the screen cued participants to repeat the nonword. After producing the nonword, the participants were asked to press the space bar to proceed to the next nonword. Participants' productions were recorded and coded off-line.

\section{Vocabulary knowledge and language experience}

All participants were administered standardized tests of English vocabulary, including the Peabody Picture Vocabulary Test-III (PPVT-III; Dunn \& Dunn, 1997) and the Expressive Vocabulary Test (EVT; William, 1997). All participants were also administered a measure of nonverbal IQ using the Matrices subtest of the Kaufman Brief Intelligence Test-2 (KBIT-2; Kaufman \& Kaufman, 2004). Finally, all participants were asked to fill out the Language Experience and Proficiency Questionnaire (Marian, Blumenfeld, \& Kaushanskaya, 2007).

\section{Coding}

\section{Word-span task}

All productions were transcribed word-for-word by a native speaker of English. Regardless of order, each production was scored as correct if the produced word was in the list. The proportion correct score was derived for each list set. Semantically similar/associated words (e.g., faculty instead of professor, judge instead of jury) or duplicated words were scored as incorrect.

\section{Digit-span tasks}

For the forward digit-span task, a participant's score was determined by the highest sequence of digits repeated accurately by a participant, with the criterion of two out of three same-length trials repeated correctly. For the backward digit-span task, a participant's score was determined similarly, with the criterion of three trials out of four repeated correctly.

\section{NWR task}

Coding and scoring were completed by a native speaker of English. Proportion correct score was obtained for each nonword by calculating the proportion of correctly produced phonemes out of total number of phonemes per nonword. Subphonemic differences between the target production and the participants' production were coded as correct. This was done in order to give bilingual participants credit for NWR performance despite differences in production due to Korean accent. Korean-accented productions of phonemes that were recognizable as the target phoneme by the native English coder were scored as correct. Conversely, all productions where phonemic differences were detected (e.g., when the produced phoneme and the target phoneme were different phonemes in English) were scored as incorrect. For example, an English nonword kadad is pronounced as $/ \mathrm{kedæd} /$, with the first vowel stressed. If a participant produced / kedæd/ with both vowels stressed, both vowels were coded as correct since they were perceived as the target vowels. However, if a participant produced /kedæd/ as /kadæd/, substituting /a/ for /e/, the phoneme /a/ was coded as incorrect, and the proportion correct score for the nonword was .8. An independent coder who was a native speaker of English coded $10 \%$ of NWR data, randomly selected from the 44 participants. Interrater agreement between the two coders ranged from $90 \%$ to $100 \%$, with an average of $97 \%$ for the simple NWR task, and from $88 \%$ to $98 \%$, with an average of $93 \%$ for the complex NWR tasks.

\section{Analyses}

Because accuracy scores for the NWR and the word span task are based on proportions, all proportion accuracy scores were first converted into arcsine values using the arcsine transformation. Furthermore, since the coding criteria for the forward digit-span and backward digit-span were different, $Z$-scores were computed for the forward and backward digit-span scores and were used for the analyses.

Four types of analyses were conducted. First, for word-span data, a $2 \times 3 \times 4$ mixed ANOVA was conducted to examine whether there was an effect of group (bilingual vs. monolingual), word length (one-, two-, and three-syllable words), and list length (5-, 10-, 15-, and 20-word lists) on word-span performance. Second, digit-span data were analyzed using a $2 \times 2$ ANOVA with group (bilingual vs. monolingual) as a between-subjects independent variable and task (forward vs. backward digit-span) as a within-subjects independent variable. Third, for NWR data, a $2 \times 3 \times 3$ mixed ANOVA was conducted to investigate whether there was an effect of group (bilingual vs. monolingual), syllable length (two-, four-, and six-syllable nonwords), and task complexity (STM, unimodal WM and crossmodal WM) on NWR performance. Fourth, for NWR data, a $2 \times 2 \times 3$ mixed ANOVA was conducted to examine whether there were differences in performance on the secondary processing tasks (animacy judgment task vs. visual search task) across groups (bilingual vs. 
monolinguals) and syllable lengths (two-, four-, and sixsyllable nonwords).

\section{Results}

Word-span performance in monolinguals and bilinguals

The mixed ANOVA yielded a main effect of list length, $F(3,123)=290.80, p<.0001, \eta_{\mathrm{p}}{ }^{2}=.88$, and significant two-way interactions between word length and group, $F(2,82)=6.10, p<.01, \eta_{\mathrm{p}}{ }^{2}=.13$, between list length and group, $F(3,123)=20.52, p<.0001$, $\eta_{\mathrm{p}}{ }^{2}=.33$, and between word length and list length, $F(6$, 246) $=4.99, p=.00, \eta_{\mathrm{p}}{ }^{2}=.11$. No other main effects or interactions were observed. Participants (bilinguals and monolinguals) were more accurate on 5-word lists $(M=1.03, S D=0.34)$ than on 10-word lists $(M=0.44, S D=0.11)$, on 10 -word lists than on 15 word lists $(M=0.32, S D=0.10)$, and on 15-word lists than on 20-word lists $(M=0.26, S D=0.09)$, with all pairwise comparisons adjusted for multiple comparisons using the Bonferroni method and significant at $p<.01$. To identify the locus of the significant interactions between word length and group and between list length and group, independent-samples $t$-tests were run comparing bilinguals and monolinguals on their word-span performance at different levels of word length (collapsed across lists) and list length (collapsed across word lengths).

Comparing bilinguals and monolinguals on their performance at different list-length levels revealed that there were significant differences between the two groups in their performance on 5-word lists, $t(42)=$ $-2.93, p<.05,15$-word lists, $t(42)=2.43, p<.05$, and 20 -word lists, $t(42)=2.47, p<.05$. Monolinguals recalled more words from 5-word lists than did bilinguals, while bilinguals recalled more words from 15word lists and 20-word lists than did monolinguals. The difference between bilinguals and monolinguals on 10word lists was not statistically significant, $t(42)=1.75$, $p=.09$ (see Fig. 1 for the visual representation of these effects).

Comparing bilinguals and monolinguals on their performance at different word-length levels revealed that on one-syllable words, monolinguals were more accurate than bilinguals, $t(42)=-2.33, p<.05$. However, there was no difference between bilinguals and monolinguals on two-syllable words, $t(42)=-0.40, p=.69$, and threesyllable words, $t(42)=1.01, p=.32$. Bilinguals and monolinguals performed comparably at the two-syllable level, but the direction of difference between the two groups for the three-syllable words shifted in favor of

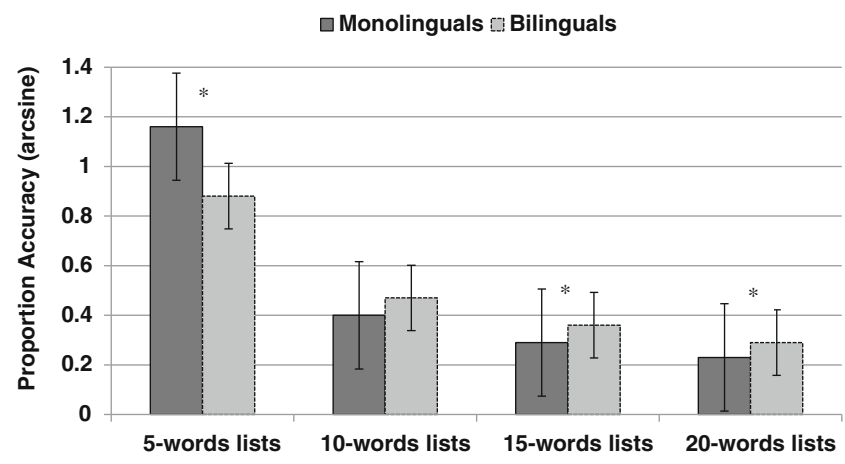

Fig. 1 Word-span task performance: Interaction between list-length and group

bilinguals, with bilinguals performing better than monolinguals (see Fig. 2 for the visual representation of these effects).

Digit-span performance in monolinguals and bilinguals

A $2 \times 2$ ANOVA revealed an interaction between task (forward digit-span vs. backward digit-span) and group (monolingual vs. bilingual), $F(1,39)=8.68, p<.01, \eta_{\mathrm{p}}{ }^{2}=.18$. There were no main effects of either task or group. To examine whether there were significant differences between groups depending on the task, Univariate ANOVAs were conducted. Univariate ANOVAs comparing bilingual and monolingual performance revealed that monolinguals outperformed bilinguals on the forward digit-span task, $F(1,39)=5.65, p<.05$, $\eta_{\mathrm{p}}{ }^{2}=.13$. However, there was an opposite trend in the backward digit-span data, with bilinguals demonstrating better, albeit not significantly so, performance than did monolinguals, $F(1,41)=1.24, p=.27, \eta_{\mathrm{p}}{ }^{2}=.03$ (see Fig. 3 for the visual representation of these effects).

NWR performance in monolinguals and bilinguals

The mixed ANOVA yielded a main effect of task, $F(2$, $84)=130.76, p<.0001, \eta_{\mathrm{p}}{ }^{2}=.76$, and a main effect of

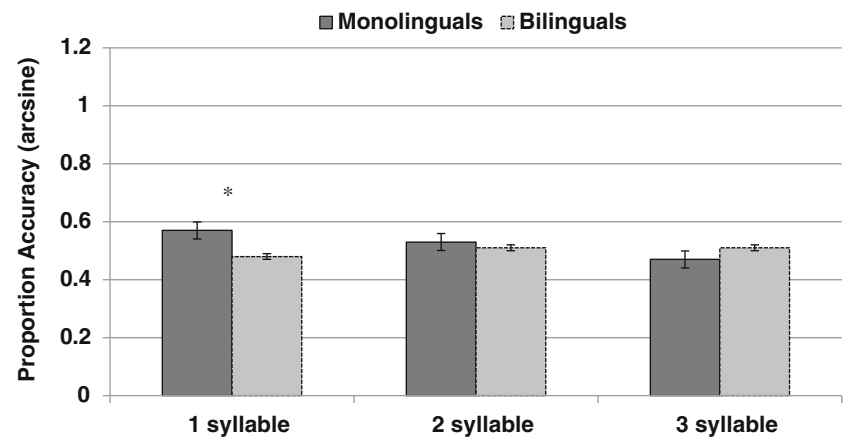

Fig. 2 Word-span task performance: Interaction between syllablelength and group 


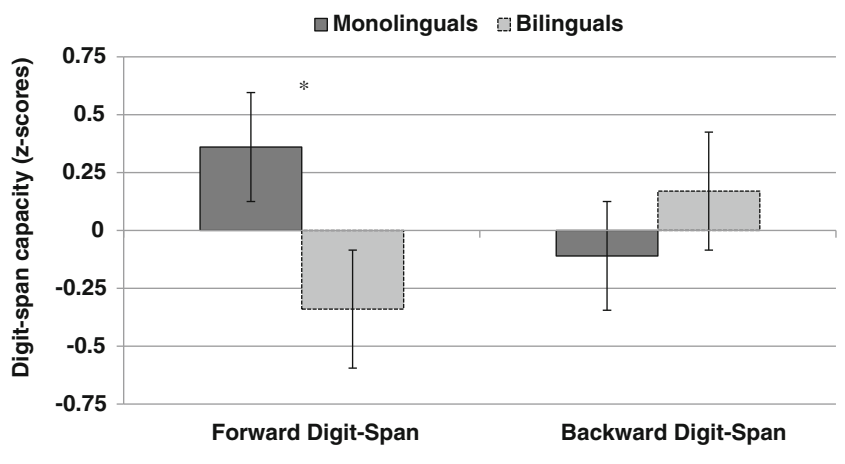

Fig. 3 Digit-span performance: Interaction between task and group

nonword syllable length, $F(2,84)=269.88, p<.0001$, $\eta_{\mathrm{p}}{ }^{2}=.87$. However, there was no effect of group, and no two-way or three-way interactions. All follow-up pairwise comparisons were adjusted for multiple comparisons using the Bonferroni method. Participants were more accurate on the STM task $(M=1.15, S E=0.02)$ than on the cross-modal WM task $(M=1.07, S E=0.02)$ and on the cross-modal WM task than on the unimodal WM task $(M=0.92, S E=0.02)$, both $p$ s $<.01$. This pattern was consistent in both groups (i.e., task complexity did not interact with group). In addition, participants were more accurate on two-syllable nonwords $(M=1.21, S E=0.02)$ than on four-syllable nonwords $(M=1.13, S E=0.02)$, on two-syllable nonwords than on six-syllable nonwords $(M=0.81, S E=0.03)$, and on four-syllable nonwords than on six-syllable nonwords, all $p$ s $<.01$. This pattern was also consistent in both groups (i.e., syllable length did not interact with group).

Animacy judgment and visual search accuracy on the WM NWR tasks

The mixed ANOVA revealed that the effects of group, $F(1,42)=0.17, p=.68, \eta_{\mathrm{p}}^{2}=.004$, task, $F(1,42)=$ $0.68, p=.41, \eta_{\mathrm{p}}^{2}=.02$, and syllable length, $F(2,84)=$ 2.78, $p=.07, \eta_{\mathrm{p}}{ }^{2}=.06$, were not significant. These results confirmed that our manipulation of the secondary processing tasks was successful, in that there were no differences between the two tasks in difficulty levels for the two groups of the participants. The lack of a syllable-length effect suggests that participants performed the two secondary tasks with the same accuracy independently of the difficulty levels of the primary task. Together, these analyses suggest that differences in NWR performance when combined with the animacy judgment task versus the visual search task are a reflection of within- vs. across-modality manipulation, rather than a reflection of higher difficulty levels associated with the animacy judgment task versus the visual search task.

\section{Discussion}

The present study investigated how bilinguals' performance on L2 phonological memory tasks compared with that of their monolingual peers. We were interested in whether discrepancies between bilinguals' and monolinguals' linguistic knowledge would seep into phonological memory performance and whether increased task difficulty would alter the patterns of difference between bilinguals and monolinguals. In line with the previous work on L2 phonological memory (e.g., Messer et al., 2010; Windsor et al., 2010), monolinguals outperformed bilinguals on some phonological memory tasks. However, this monolingual, L1 advantage was limited to tasks involving the easiest levels of task difficulty (shortest words/lists on the list-memory task; forward digit-span task) and to tasks involving lexical-semantic knowledge (list memory and digit-span tasks). Bilinguals and monolinguals did not differ in their performance on the NWR task. Moreover, the differences between bilinguals and monolinguals disappeared, and even reversed, at the most difficult levels of the digitspan and the list memory tasks. Together, these findings indicate that previously identified discrepancies between bilingual and monolingual phonological memory skills must be reconceptualized and reinterpreted.

We observed superior monolingual performance at the easiest level of task difficulty for the digit-span and the list-memory tasks. However, for the NWR task, the overall ANOVA failed to reveal a significant interaction between task and group. The finding that monolinguals and bilinguals did not differ in their performance on the NWR task is at odds with previous studies of NWR performance in L2 versus L1 (e.g., Masoura \& Gathercole, 1999; Messer et al., 2010). For example, Masoura and Gathercole (1999) demonstrated that L1 NWR performance was significantly higher than L2 NWR performance, and Thorn et al. (2005) found that monolinguals outperformed bilinguals on the NWR task where the nonwords were constructed according to the phonotactic rules of the monolinguals' L1. There are a number of possible explanations for the lack of group differences on the NWR task in the present study.

First, it is possible that the majority of the conditions for the NWR task (e.g., all the syllable-length levels of the two dual tasks and the longest syllablelength level of the simple NWR task) were so difficult, that they equalized the group differences and flattened the overall group effects in the omnibus analysis. The examination of Fig. 4, where the NWR data are graphed, reveals that monolinguals did outperform bilinguals at the shortest length levels on the simple task (on two-syllable and four-syllable nonwords). 

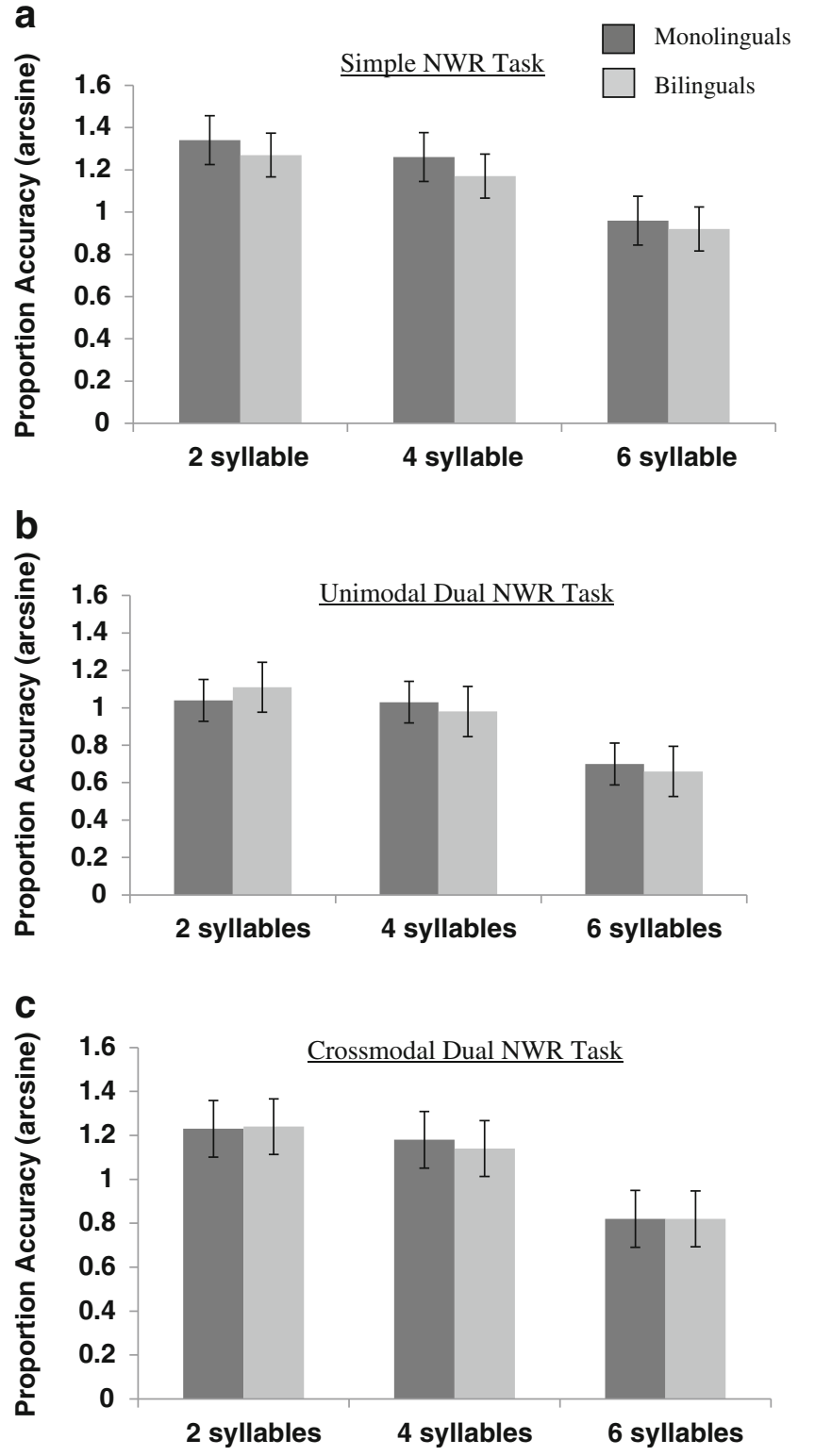

Fig. 4 Simple nonword repetition (NWR), unimodal dual-task NWR, and cross-modal dual-task NWR performance

Moreover, the group differences were statistically significant when independent-samples $t$-tests were conducted on these two NWR performance measures. However, because all the comparisons for the other NWR measures yielded comparable performance levels for bilinguals and monolinguals, the two comparisons where group differences were observed (two-syllable and four-syllable levels for the simple NWR task) failed to reach significance in the overall ANOVA. Second, it is likely that the low wordlikeness of the nonwords contributed to the lack of group differences on the NWR task. The nonwords used as stimuli in the present study were specifically designed to bear little resemblance to the real words of English, both in terms of prosodic structure and in terms of phonotactics (Gupta et al., 2004). This low overlap between the phonological structure of the nonwords and the real English words likely yielded the flat group effects in the NWR data, since both monolinguals and bilinguals could make little use of prior English knowledge to support NWR performance.

For the word-span and the digit-span tasks, there was a clear interaction between task difficulty and group in the overall ANOVAs. We observed that an increase in the difficulty level eliminated the monolingual advantage on the digit-span task, while for the word-span task, an increase in the difficulty level actually revealed a monolingual disadvantage. In conceptualizing the study, we equated the increase in the difficulty level of the phonological memory task with the increase in the involvement of the domain-general executive control processes (e.g., Cowan, 2001; Engle et al., 1999). Therefore, we interpret the interaction between group and difficulty level observed in the word-span and digit-span data to suggest that bilinguals and monolinguals are differentially affected by the involvement of the central executive in the memory process. Specifically, we propose that the reversal of monolingual/bilingual differences observed in the present study at different difficulty levels of the phonological memory tasks is a reflection of the dynamics between linguistic knowledge and domain-general executive control processes.

While linguistic knowledge may be more robust in monolinguals than in bilinguals (especially those tested in their L2; see, e.g., Perani et al., 2003; Portocarrero et al., 2007), executive functioning (especially the ability to control attention) may be more robust in bilinguals than in monolinguals (e.g., Bialystok, 1999; Bialystok et al., 2004). For the simple memory tasks, where the central executive is less involved and performance largely relies on short-term storage (activated information in LTM), it is the extent of linguistic knowledge that dictates performance. Here, monolinguals clearly have an advantage over bilinguals, whose levels of L2 lexical-semantic knowledge are lower. For the more difficult memory tasks, where the central executive becomes more involved and performance relies on both the short-term storage (activated information in LTM) and the efficiency of the central executive (or focused attention), bilinguals may have an advantage over monolinguals. In other words, a more efficient central executive compensates for the lower levels of linguistic knowledge as the tasks get more difficult and overtakes linguistic knowledge in constraining the phonological memory performance once the amount of information exceeds the capacity limitations of the memory system. 
As a result, bilinguals outperform or perform comparably to monolinguals on the difficult phonological memory tasks.

An alternative interpretation of the shifting group differences in the digit-span and the word-span data, with monolinguals outperforming bilinguals at the easier (but not the more difficult) levels of the phonological memory tasks is that monolinguals are better able to take advantage of the reintegration processes than are bilinguals, at least at the easiest levels of task difficulty. Redintegration theories suggesting that long-term linguistic knowledge can support STM function have been traditionally used for interpreting L2 disadvantages on phonological memory tasks like the word-span task (e.g., Brown \& Hulme, 1992; Thorn \& Gathercole, 1999, 2001; Thorn, Gathercole, \& Frankish, 2002). Specifically, according to the redintegration account of LTM/STM interactions (e.g., Gathercole et al., 1999; Schweickert, 1993; Thorn et al., 2005), it is possible to repair incomplete information in the STM storage using permanent lexical representations in LTM. For example, findings of superior memory performance for real words than for nonwords have been explained in terms of redintegration (e.g., Brown \& Hulme, 1995; Thorn \& Gathercole, 2001).

Using the redintegration framework (e.g., Gathercole et al., 1999; Schweickert, 1993; Thorn et al., 2005) to explain the discrepancies between L1 and L2 phonological memory skills in bilinguals leads to a hypothesis that bilingual speakers may be less able to take advantage of redintegration mechanisms when performing phonological memory tasks in their L2 because of the relatively weak L2 linguistic representations in the LTM. The explanation for the reduced differences between monolinguals' and bilinguals' digit-span and list-memory performance with an increase in difficulty levels would then be that with the increase in the difficulty level of the task, the degree to which the stimuli activate the LTM linguistic representations decreases. In the present study, as the word length increased in the word-span task, the phonotactic probability and neighborhood density of the words decreased. It is possible, then, that decreased activation of the LTM associated with decreased phonotactic probability and neighborhood density, rather than increased reliance on the central executive, is what reduced the L1/L2 performance gap at the more difficult levels of the word-span and the digit-span tasks.

There are two reasons why this explanation is unlikely or at least insufficient to account for the findings obtained in the present study. First, the reduction in L1/ L2 performance levels was also observed on the backward digit-span task, as compared with the forward digit-span task. Given that the backward digit-span task involved the same stimuli as the forward digit-span task, it is unlikely that the two tasks relied on the LTM to different degrees. Instead, it is likely that the increased involvement of the central executive in backward digitspan performance is what reduced the difference between bilinguals and monolinguals. Second, phonotactic probability and neighborhood density of words in the word-span task were controlled across lists and varied only across the different syllable-length levels. If reduced reliance on LTM was at the root of improved L2 performance, we would expect the reversal to take place at the longest syllable-length level. Yet the reversal of bilingual/monolingual differences was observed only when list length increased and was not observed when syllable length increased. Therefore, our preferred interpretation for the fluctuations between bilingual and monolingual levels of performance on more versus less difficult phonological memory tasks is that an increase in the difficulty level of the task elevates the involvement of domain-general central executive mechanisms in performance. This ameliorates the disadvantages associated with performing the phonological memory tasks in the L2 and, in fact, can yield advantages in bilinguals on one particular task-the word-span task. But why did bilinguals in our study outperform monolinguals only at the difficult levels of the word-span task, and not on the digit-span or the NWR task? There are a few possible explanations for this finding.

For example, it is possible that the manipulation of the difficulty level was more successful for the wordspan task than for the NWR or the digit-span task. The tasks were not designed in a way that would enable us to equalize the difficulty levels across tasks, and the differences across the difficulty levels within a task and across tasks were not documented independently from the tasks themselves. In the future, it would be useful to replicate the present findings with a different population in order to examine whether the difficulty hierarchy established here generalizes across experiments and participants. In the context of the present study, it is possible that the NWR task never became difficult enough to induce the involvement of the central executive and, thus, to reverse the direction of the bilingual/monolingual differences.

Furthermore, it is possible that the different patterns of results across the three tasks are rooted in the different methods by which task difficulty was manipulated. We manipulated the difficulty of the word-span task across two parameters: syllable length and list length. We found that group differences reversed (with bilinguals outperforming monolinguals) only with the increase in list length, but not with the increase in 
syllable length. An increase in the syllable length equalized bilingual and monolingual levels of performance but did not reveal a bilingual advantage. Similarly, we manipulated the NWR task by increasing the syllable length and by combining the primary NWR task with verbal or nonverbal secondary tasks and did not find bilingual advantages at the more difficult levels of the task. Therefore, it appears that the increased efficiency of the central executive associated with bilingualism is more likely to influence STM performance when the number of to-be-remembered meaningful units increases than when the number of to-be-remembered phonological units (i.e., syllables) increases. Generally, the dissociation between the word-span task and the NWR task suggests that the involvement of the central executive elevates bilingual performance over monolingual performance only when the task involves meaningful information. That is, perhaps a more efficient central executive coupled to the ability to take advantage of the available semantic network is necessary to observe bilingual advantages on the L2 phonological memory tasks.

In conclusion, the findings of the present study suggest that phonological memory differences between bilinguals and monolinguals crucially depend on the type of the phonological memory task (and the degree to which the task indexes lexical-semantic knowledge) and the difficulty of the task (and the degree to which the task involves a domain-general central executive system). At the easiest levels of task difficulty, monolinguals tend to outperform bilinguals on L2 phonological memory tasks, likely because of the more robust linguistic representations established in the L1 versus the L2. Moreover, at the easiest levels of task difficulty, monolinguals are more likely to outperform bilinguals on the phonological memory tasks like the word-span and the digit-span that involve target language lexicalsemantic knowledge than on tasks like the NWR, which relies minimally on target language lexical-semantic knowledge. With the increase in the difficulty level, the differences between bilinguals and monolinguals diminish, likely because of the involvement of the domain-general central executive. Only by comparing bilingual and monolingual performance is it possible to observe the fluid dynamics between linguistic knowledge and central executive in the phonological memory system.

Acknowledgements This research was supported by the University of Wisconsin-Madison Graduate School WARF Grant to Margarita Kaushanskaya. The authors are grateful to Anna Saucerman, Stephanie Van Hecke, Jenna Osowski, Julie Winer, and Marissa Stern for help with data collection and data coding.

\section{Appendix 1}

Table 5 Word-span task stimuli

\begin{tabular}{|c|c|c|c|}
\hline & $\begin{array}{l}\text { One-syllable } \\
\text { words }\end{array}$ & $\begin{array}{l}\text { Two-syllable } \\
\text { words }\end{array}$ & $\begin{array}{l}\text { Three-syllable } \\
\text { words }\end{array}$ \\
\hline \multirow[t]{5}{*}{ 5-word lists } & BEAR & RACKET & CABINET \\
\hline & PUMP & WHISTLE & FACTORY \\
\hline & CROOK & TEACHER & MINISTER \\
\hline & WIRE & MOTOR & POLICEMAN \\
\hline & HAT & FOOTBALL & VIOLIN \\
\hline \multirow[t]{10}{*}{ 10-word lists } & FAN & ANTIQUE & CANDIDATE \\
\hline & POLE & OUTFIT & CIGARETTE \\
\hline & LUMP & GRAVEL & ENGINEER \\
\hline & CROW & CHINA & GRANDMOTHER \\
\hline & RAY & VOTER & INSTRUMENT \\
\hline & SHOT & PAINTING & MONUMENT \\
\hline & TUBE & MUSCLE & OPENING \\
\hline & BELT & SINGER & PHOTOGRAPH \\
\hline & EAR & FILLING & TREASURER \\
\hline & WINE & LADY & VEHICLE \\
\hline \multirow[t]{15}{*}{ 15-word lists } & BEAM & AXLE & AVENUE \\
\hline & CROSS & BOTTLE & BEVERAGE \\
\hline & DOG & CANAL & CONVENTION \\
\hline & FLAG & CEILING & FURNITURE \\
\hline & GOWN & DIAMOND & ELEPHANT \\
\hline & HAIR & FABRIC & GRADUATE \\
\hline & INCH & GARBAGE & HONEYMOON \\
\hline & LAWN & GIANT & INSTITUTE \\
\hline & MOTH & JACKET & MUSICIAN \\
\hline & PRINCE & MASTER & OFFICER \\
\hline & RUST & NATIVE & PINEAPPLE \\
\hline & STONE & OVEN & RADIO \\
\hline & TEAR & POET & REGISTER \\
\hline & THORN & ENTRANCE & SALARY \\
\hline & YACHT & TRACTOR & TELESCOPE \\
\hline \multirow[t]{20}{*}{ 20-word lists } & $\mathrm{ASH}$ & ANGLE & APARTMENT \\
\hline & BRICK & BARREL & BACTERIA \\
\hline & EGG & COFFIN & CAMERA \\
\hline & CHAIN & DISEASE & CHOCOLATE \\
\hline & $\mathrm{COACH}$ & ESSAY & DETECTIVE \\
\hline & DRILL & FOREST & ENVELOPE \\
\hline & FAN & HOUSEHOLD & FOREIGNER \\
\hline & GRASS & JURY & GALLERY \\
\hline & HORN & LOBSTER & GENTLEMAN \\
\hline & ISLE & MOVIE & IVORY \\
\hline & JUDGE & ONION & LIBRARY \\
\hline & KNIFE & PIGEON & MEDICINE \\
\hline & LAKE & RABBI & NEWSPAPER \\
\hline & MOLD & SHOULDER & ORCHESTRA \\
\hline & SHEEP & SIGNAL & PROFESSOR \\
\hline & PATH & TIRE & RECITAL \\
\hline & RIB & VILLAGE & SUBMARINE \\
\hline & SPADE & WALNUT & TELEPHONE \\
\hline & TRAIN & WEDDING & UNIFORM \\
\hline & VEST & YELLOW & VOLCANO \\
\hline
\end{tabular}


Appendix 2

Table 6 Nonword repetition task stimuli (three sets of lists)

\begin{tabular}{|c|c|c|c|c|c|}
\hline $2 \mathrm{SYL}$ & IPA & $4 \mathrm{SYL}$ & IPA & $6 \mathrm{SYL}$ & IPA \\
\hline gilare & gIle. & kugadoset & kugedowset & doserarosepuk & dowsi. $e_{\text {a asipək }}$ \\
\hline gonepe & gownip & kedekaloge & kidskelowg & bisetegekirite & bajsitig\&kaj.ıəjt \\
\hline punel & pun $\varepsilon 1$ & bisodatese & bajsadetis & ketesoseporole & kitisows\&pow. \\
\hline pomive & powmajv & turisedute & turajsidut & gusutiporoneke & gusutajpow.ıunik \\
\hline kemote & kemowt & pugisisas & 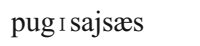 & tiradigenitote & taj. edajginajtowt \\
\hline kupede & kupid & dutenelage & dutenileg & kolesasosatab & kolisesasitæb \\
\hline padod & pedad & digurulel & dajguxuls1 & terokesisisor & ti.. owkisajsajs $\supset$. \\
\hline difed & daif\&d & botenenod & bowtuninad & gifenokuvidive & gajfinowkəvidajv \\
\hline kovete & kowvit & tokisekov & towkisikav & dekediderakete & dikidajd rekit \\
\hline titeke & tajtik & bepituseb & bipaituseb & beselatagorar & bisiletegowıал \\
\hline balide & bælajd & pokosilas & powkasajlæs & tenivorilekeg & tinajvow.ajlikeg \\
\hline patus & pætəs & bokenidine & bowkinajdin & bokikoletinef & bowkajkowletajn\&f \\
\hline kivik & kibik & benodufop & binowdufap & gimekofenamod & gajmikof\&nemad \\
\hline tatime & tætajm & peniranane & pinitenen & tetaditotunom & titedutowtunam \\
\hline todem & towdem & gidodelar & gajdownila. & betitalenotine & bitajtelinowtajn \\
\hline dinume & dajnum & tilekamat & tajlikemæt & badidadodukik & bedajdedowduk Ik \\
\hline $2 \mathrm{SYL}$ & IPA & $4 \mathrm{SYL}$ & IPA & $6 \mathrm{SYL}$ & IPA \\
\hline gurope & guı owp & diritepev & daj. I tipev & pimetonededud & pajmitownckidəd \\
\hline dalid & delid & kirisolep & kaj. ajsowlep & gabasefepelede & gebesifipilid \\
\hline pedede & pedid & kikudanese & kajkədajnis & banemerenesane & benumi $x$ \&nisen \\
\hline kadad & kedæd & detenutese & dipunudægik Ik & kiderikidokon & kajdiıajkidowkan \\
\hline kumit & kumit & katatupel & ketætupel & pugetisitibuke & pugitajsitajbuk \\
\hline bafere & bæfi. & telokureg & tilowkuı\&g & depenatidiken & dipinet I dajkæn \\
\hline podud & powdəd & kokotedake & kokotidek & depunudagekik & dipunudægik I k \\
\hline kenupe & kinup & bamitevose & bemajtivows & kanesekenedas & kenisikunidæs \\
\hline tapune & tepun & dolegesif & dolegisef & panemalakilek & penimelekajlık \\
\hline koseg & kowseg & kimodafite & kajmowdefəjt & kepotekisoden & kipowtikajsowd in \\
\hline kiles & $\mathrm{kI} l \varepsilon \mathrm{s}$ & bogakipis & bowgekajp is & korogodesikede & ko.ıowgowdisajkid \\
\hline pasole & pesol & gedipeneke & gid I pinik & bakidinetorope & bekajdajnstow towp \\
\hline kotase & kates & bekefuros & biksfu. as & kanokegarasole & kenowkige.resol \\
\hline kudile & kədajl & boneteripe & bowniti. əjp & diditivavemite & dajdajtajvæviməjt \\
\hline dekek & $\mathrm{d} \varepsilon \mathrm{k} \varepsilon \mathrm{k}$ & kobosusake & kowbowsusek & tapenodutifame & tepinowdutajfem \\
\hline konete & kownit & detigukob & ditajgukab & kepanasekelule & kipenesikilul \\
\hline $2 \mathrm{SYL}$ & IPA & $4 \mathrm{SYL}$ & IPA & $6 \mathrm{SYL}$ & IPA \\
\hline basim & bæsım & benafetaf & binefitæf & baripenalisute & be.лajpinelajsut \\
\hline belose & bilows & dadanemok & dedænimak & binikemulosod & bajnajkimulowsad \\
\hline berot & brat & dadasimin & dedejsajm In & bupotosanenet & bupowtowsæninet \\
\hline bulon & bulan & dofegotoge & dowf\&gowtowg & dolarobatelose & dowle. obetilows \\
\hline kemig & kimig & ganesisote & genisajsowt & donosenesanut & downowsinisajnət \\
\hline kivef & kivef & kedenerete & kidenisit & dudatotitigat & dudetowtajtajgæt \\
\hline kogos & kowgas & kokolanad & kokolenæd & gategalosesas & getigelowsisæs \\
\hline kubude & kubud & kunipomim & kunajpowmim & gekipireninat & gikajpaj. inajnæt \\
\hline pakem & pek\&m & kutogofine & kutagowfajn & kerositumidise & ki..owsajtumajd js \\
\hline pegut & pegət & patekoreg & petckow. & kikegelegidev & kajkigilegajdev \\
\hline pimin & pimin & pimovenise & pajmowvinajs & kilidunudoves & kajlajdunədowves \\
\hline punop & pənap & piniserof & pajnajsi.ıaf & kobetevafefat & kowbitivæfifæt \\
\hline tadim & tæd Im & tagopetere & tegapiti. & pekikipebarele & pikajkajp\&be..il \\
\hline tafore & tæfo. & tamabokuse & temæbowkus & tefevoferibete & tifivowfəajbit \\
\hline tebon & teban & tesinetil & tis I nitil & tetegatudodir & titigetudowdi. \\
\hline terid & ti.i Id & tivoditure & tajvadajtuə & tetomelanenuse & titowmileninus \\
\hline
\end{tabular}




\section{References}

Archibald, L. M. D., \& Gathercole, S. E. (2006). Nonword repetition: A comparison of tests. Journal of Speech, Language, and Hearing Research, 49, 970-983. doi:10.1044/1092-4388(2006/070

Baddeley, A. D. (1986). Working memory. New York: Oxford University Press.

Baddeley, A. D. (2000). The episodic buffer: A new component of working memory? Trends in Cognitive Sciences, 4, 417-423. doi:10.1016/S1364-6613(00)01538-2

Baddeley, A. D. (2001). The concept of episodic memory. Philosophical Transactions of the Royal Society of London. Series B, Biological Sciences, 356(1413), 1345-1350. doi:10.1098/rstb.2001.0957

Baddeley, A. D. (2003). Working memory: Looking back and looking forward. Nature Reviews Neuroscience, 4, 829-839. doi:10.1038/ nrn1201

Baddeley, A. D., Gathercole, S., \& Papagno, C. (1998). The phonological loop as a language learning device. Psychological Review, 105, 158-173. doi:10.1037/0033-295X.105.1.158

Baddeley, A. D., \& Hitch, G. J. (1974). Working memory. In G. Bower (Ed.), The Psychology of Learning and Motivation (pp. 47-90). New York: Academic Press.

Baddelely, A. D., Tomson, N., \& Buchanan, M. (1975). Word length and the structure of short-term memory. Journal of Verbal Learning and Verbal Behavior, 14, 575-589. doi:10.1016/ S0022-5371(75)80045-4

Bialystok, E. (1999). Cognitive complexity and attentional control in the bilingual mind. Child Development, 70, 636-644. doi:10.1111/1467-8624.00046

Bialystok, E., Craik, F. I. M., Klein, R., \& Viswanathan, M. (2004). Bilingualism, aging, and cognitive control: Evidence from the Simon task. Psychology and Aging, 19, 290-303. doi:10.1037/ 0882-7974.19.2.290

Bialystok, E., Craik, F. I. M., \& Ryan, J. (2006). Executive control in a modified anti-saccade task: Effects of aging and bilingualism. Journal of Experimental Psychology: Learning, Memory, and Cognition, 32, 1341-1354. doi:10.1037/0278-7393.32.6.1341

Bialystock, E., \& Feng, X. (2009). Language proficiency and executive control in proactive interference: Evidence from monolingual and bilingual children and adults. Brain and Language, 109, 93-100. doi:10.1016/j.bandl.2008.09.001

Bialystok, E., \& Shapero, D. (2005). Ambiguous benefits: The effect of bilingualism on reversing ambiguous figures. Developmental Science, 8(6), 595-604. doi:10.1111/j.1467-7687.2005.00451.x

Blumenfeld, H., \& Marian, V. (2011). Bilingualism influences inhibitory control in auditory comprehension. Cognition, 118(2), 245257. doi:10.1016/j.cognition.2010.10.012

Brown, G. D. A., \& Hulme, C. (1992). Cognitive psychology and second language processing: The role of short-term memory. In R. J. Harris (Ed.), Advances in psychology: Vol. 83. Cognitive approaches to bilingualism (pp. 105-121). Amsterdam: NorthHolland. doi:10.1016/S0166-4115(08)61490-9

Brown, G. D. A., \& Hulme, C. (1995). Modeling item length effects in memory span: No rehearsal needed? Journal of Memory and Language, 34, 594-621. doi:10.1006/jmla.1995.1027

Brysbaert, M., \& New, B. (2009). Moving beyond Kucera and Francis: A critical evaluation of current word frequency norms and the introduction of a new and improved word frequency measure for American English. Behavior Research Methods, 41, 977-990. doi:10.3758/BRM.41.4.977

Cantor, J., Engle, R. W., \& Hamilton, G. (1991). Short-term memory, working memory, and verbal abilities: How do they relate? Intelligence, 15, 229-246. doi:10.1016/0160-2896 (91)90032-9
Cheung, H. (1996). Nonword span as a unique predictor of secondlanguage vocabulary learning. Developmental Psychology, 32(5), 867-873. doi:10.1037/0012-1649.32.5.867

Christoffels, I. K., \& de Groot, A. M. B. (2005). Simultaneous interpreting: A cognitive perspective. In J. F. Kroll \& A. M. B. de Groot (Eds.), Handbook of bilingualism: Psycholinguistic approaches (pp. 454-479). New York: Oxford University Press.

Conklin, H. M., Curtis, C. E., Katsanis, J., \& Iacono, W. G. (2000). Verbal working memory impairment in schizophrenia patients and their first-degree relatives: Evidence from the digit span task. The American Journal of Psychiatry, 157, 275-277. doi:10.1176/ appi.ajp.157.2.275

Costa, A., Hernandez, M., \& Sebastián-Gallés, N. (2008). Bilingualism aids conflict resolution: Evidence from the ANT task. Cognition, 106, 59-86. doi:10.1016/j.cognition.2006.12.013

Cowan, N. (1988). Evolving conceptions of memory storage, selective attention, and their mutual constraints within the human information processing system. Psychological Bulletin, 104, 163-191. doi:10.1037/0033-2909.104.2.163

Cowan, N. (1999). An embedded-processes model of working memory. In A. Miyake \& P. Shah (Eds.), Models of working memory: Mechanisms of active maintenance and executive control (pp. 62101). Cambridge, UK: Cambridge University Press.

Cowan, N. (2001). The magical number 4 in short-term memory: A reconsideration of mental storage capacity. The Behavioral and Brain Sciences, 24, 87-114. doi:10.1017/S0140525X01003922

Damian, M. F. (2004). Asymmetries in the processing of arabic digits and number words. Memory \& Cognition, 31, 164-171. doi:10.3758/BF03195829

Daneman, M., \& Carpenter, P. A. (1980). Individual differences in working memory and reading. Journal of Verbal Learning and Verbal Behavior, 19, 450-466. doi:10.1016/S0022-5371 (80)90312-6

Dehaene, S., \& Mehler, J. (1992). Cross-linguistic regularities in the frequency of number words. Cognition, 43, 1-29. doi:10.1016/ 0010-0277(92)90030-L

Dunn, L. M., \& Dunn, L. M. (1997). Peabody Picture Vocabulary Test (3rd ed.). Circle Pines, MN: American Guidance Service.

Edwards, J., Beckman, M. E., \& Munson, B. (2004). The interaction between vocabulary size and phonotactic probability effects on children's production accuracy and fluency in nonword repetition. Journal of Speech, Language, and Hearing Research, 47, 421436. doi:10.1044/1092-4388(2004/034

Engle, R. W., Kane, M. J., \& Tuholski, S. W. (1999). Individual differences in working memory capacity and what they tell us about controlled attention, general fluid intelligence, and function of the prefrontal cortex. In A. Miyake \& P. Shah (Eds.), Models of Working Memory (pp. 28-61). New York: Cambridge University Press.

Engle, R. W., Nations, J. K., \& Cantor, J. (1990). Is "working memory capacity" just another name for word knowledge? Journal of Educational Psychology, 82, 799-804. doi:10.1037/00220663.82.4.799

Engle, R. W., Tuholski, S. W., Laughlin, J. E., \& Conway, A. R. A. (1999). Working memory, short-term memory and general fluid intelligence: A latent variable approach. Journal of Experimental Psychology. General, 128, 309-331. doi:10.1037/00963445.128.3.309

Gathercole, S. E. (1995). Is nonword repetition a test of phonological memory or long-term knowledge? It all depends on the nonwords. Memory \& Cognition, 23, 83-94. doi:10.3758/BF03210559

Gathercole, S. E., \& Adams, A.-M. (1993). Phonological working memory in very young children. Developmental Psychology, 29, 770-778. doi:10.1037/0012-1649.29.4.770

Gathercole, S. E., \& Baddeley, A. D. (1989). Evaluation of the role of phonological STM in the development of vocabulary in children: 
A longitudinal study. Journal of Memory and Language, 28, 200 213. doi:10.1016/0749-596X(89)90044-2

Gathercole, S. E., \& Baddeley, A. D. (1990). The role of phonological memory in vocabulary acquisition: A study of young children leaning new names. British Journal of Psychology, 81, 439-454. doi:10.1111/j.2044-8295.1990.tb02371.x

Gathercole, S. E., Frannkish, C. R., Pickering, S. J., \& Peaker, S. H. (1999). Phonotactic influences on serial recall. Journal of Experimental Psychology: Learning, Memory, and Cognition, 25, 84-95. doi:10.1037/0278-7393.25.1.84

Gathercole, S. E., Willis, C., Emslie, H., \& Baddeley, A. (1991). The influences of syllables and wordlikeness on children's repetition of nonwords. Applied PsychoLinguistics, 12, 349-367.

Girbau, D., \& Schwartz, R. G. (2007). Non-word repetition in Spanishspeaking children with specific language impairment (SLI). International Journal of Language \& Communication Disorders, 42, 59-75. doi:10.1080/13682820600783210

Gupta, P., Lipinski, J., Abbs, B., Lin, P.-H., Aktunc, M. E., Ludden, D., Martin, N., \& Newman, R. (2004). Space Aliens and Nonwords: Stimuli for Investigating the Learning of Novel Word-Meaning Pairs. Behavioral Research Methods, Instruments, and Computers, 36, 699-703. doi:10.3758/BF03206540

Harrington, M., \& Sawyer, M. (1992). L2 working memory capacity and L2 reading skill. Studies in Second Language Acquisition, 14, 25-38. doi:10.1017/S0272263100010457

Heitz, R., \& Engle, R. (2007). Focusing the spotlight: Individual differences in visual attention control. Journal of Experimental Psychology. General, 136(2), 217-240. doi:10.1037/00963445.136.2.217

Hulme, C., Maughan, S., \& Brown, G. D. A. (1991). Memory for familiar and unfamiliar words: Evidence for a long-term memory contribution to short-term memory span. Journal of Memory and Language, 30, 685-701. doi:10.1016/0749-596X(91)90032-F

Hulme, C., Roodenrys, S., Schweickert, R., Brown, G. D. A., Martin, S., \& Stuart, G. (1997). Word-frequency effects on short-term memory tasks: Evidence for a redintegration process in immediate serial recall. Journal of Experimental Psychology: Learning, Memory, and Cognition, 23(5), 1217-1232. doi:10.1037/02787393.23.5.1217

Hulme, C., Thomson, N., Muir, C., \& Lawrence, A. (1984). Speech rate and the development of short-term memory. Journal of Experimental Child Psychology, 38, 241-253. doi:10.1016/ 0022-0965(84)90124-3

Just, M. A., \& Carpenter, P. A. (1992). A capacity theory of comprehension: Individual differences in working memory. Psychological Review, 98, 122-149. doi:10.1037/0033-295X.99.1.122

Kail, R., \& Hall, L. K. (2001). Distinguishing short-term memory from working memory. Memory \& Cognition, 29, 1-9. doi:10.3758/ BF03195735

Kane, M. J., Bleckley, M. K., Conway, A. R. A., \& Engle, R. W. (2001). A controlled-attention view of working-memory capacity. Journal of Experimental Psychology. General, 130, 169-183. doi:10.1037/0096-3445.130.2.169

Kane, M., \& Engle, R. (2003). Working-memory capacity and the control of attention: The contributions of goal neglect, response competition, and task set to stroop interference. Journal of Experimental Psychology. General, 132(1), 47-70. doi:10.1037/ 0096-3445.132.1.47

Kane, M. J., Hambrick, D. Z., Tuholski, S. W., Wilhelm, O., Payne, T. W., \& Engle, R. W. (2004). The generality of working memory capacity: A latent-variable approach to verbal and visuospatial memory span and reasoning. Journal of Experimental Psychology. General, 133, 189-217. doi:10.1037/00963445.133.2.189

Kaufman, A. S., \& Kaufman, N. L. (2004). Kaufman Brief Intelligence Test (2nd ed.). Bloomington, MN: Pearson, Inc.
LaPointe, L. B., \& Engle, R. W. (1990). Simple and complex word spans as measures of working memory capacity. Journal of Experimental Psychology: Learning, Memory, and Cognition, 16, 1118-1133. doi:10.1037/0278-7393.16.6.1118

Lovatt, P., Avons, S. E., \& Masterson, J. (2000). The word - length effect and disyllabic words. Quarterly Journal of Experimental Psychology, 53A, 1-22. doi:10.1080/027249800390646

Majerus, S., Heiligenstein, L., Gautherot, N., Poncelet, M., \& Van der Linden, M. (2009). The impact of auditory selective attention on verbal short-term memory and vocabulary development. Journal of Experimental Child Psychology, 103, 66-86. doi:10.1016/ j.jecp.2008.07.004

Marian, V., Bartolotti, J., Chabal, S., \& Shook, A. (2012). CLEARPOND: Cross-Linguistic Easy-Access Resource for Phonological and Orthographic Neighborhood Density (http:// clearpond.northwestern.edu/). (http://clearpond.northwestern.edu/ \%29.) PLoS One. doi:10.1371/journal.pone.0043230

Marian, V., Blumenfeld, H. K., \& Kaushanskaya, M. (2007). The Language Experience and Proficiency Questionnaire (LEAP-Q): Assessing language profiles in bilinguals and mutilinguals. Journal of Speech, Language, and Hearing Research, 50, 940 967. doi:10.1044/1092-4388(2007/067

Masoura, E., \& Gathercole, S. E. (1999). Phonological short-term memory and foreign vocabulary learning. International Journal of Psychology, 34, 383-388. doi:10.1080/002075999399738

Messer, M., Leseman, P., Boom, J., \& Mayo, A. (2010). Phonotactic probability effect in nonword recall and its relationship with vocabulary in monolingual and bilingual preschoolers. Journal of Experimental Child Psychology, 105(4), 306-323. doi:10.1016/ j.jecp.2009.12.006

Mezzacappa, E. (2004). Alerting, orienting, and executive attention: Developmental properties and sociodemographic correlates in an epidemiological sample of young, urban children. Child Development, 75(5), 1373-1386. doi:10.1111/j.14678624.2004.00746.x

Michas, I. C., \& Henry, L. A. (1994). The link between phonological memory and vocabulary acquisition. British Journal of Developmental Psychology, 12, 147-163. doi:10.1111/j.2044835X.1994.tb00625.x

Munson, B. (2001). Phonological pattern frequency and speech production in children and adults. Journal of Speech, Language, and Hearing Research, 44, 778-792. doi:10.1044/1092-4388(2001/061

Perani, D., Abutalebi, J., Paulesu, E., Brambati, S., Scifo, P., Cappa, S. F., \& Fazio, F. (2003). The role of age of acquisition and language usage in early, high-proficient bilinguals: An fMRI study during verbal fluency. Human Brain Mapping, 19, 170-182. doi:10.1002/hbm. 10110

Poirier, M., \& Saint-Aubin, J. (1995). Memory for related and unrelated words: Further evidence on the mnuence of semantic factors in immediate serial recall. The Quarterly Journal of Experimental Psychology, 48A, 384-404.

Portocarrero, J. S., Burright, R. G., \& Donovick, P. J. (2007). Vocabulary and verbal fluency of bilingual and monolingual college students. Archives of Clinical Neuropsychology, 22, 415-422. doi:10.1016/j.acn.2007.01.015

Roberts, P. M., Garcia, L. J., Desrochers, A., \& Hernandez, D. (2002). English performance of proficient bilingual adults on the Boston Naming Test. Aphasiology, 16, 635-645. doi:10.1080/ 02687030244000220

Schweickert, R. (1993). A multinomial processing tree model for degradation and redintegration in immediate recall. Memory \& Cognition, 21, 167-175. doi:10.3758/BF03202729

Service, E. (1992). Phonology, working memory, and foreign-language learning. Quarterly Journal of Experimental Psychology, 45A, 21-50.

Shah, P., \& Miyake, A. (1996). The separability of working memory resources for spatial thinking and language processing: An 
individual differences approach. Journal of Experimental Psychology. General, 125, 4-27. doi:10.1037/0096-3445.125.1.4

Smith, S., Mann, V. A., \& Shankweiler, D. (1986). Spoken sentence comprehension in good and poor readers: a study with the token test. Cortex, 22, 627-632.

Swanson, H. L., \& Berninger, V. (1995). The role of working memory in skilled and less skilled readers' comprehension. Intelligence, 21, 83-108. doi:10.1016/0160-2896(95)90040-3

Thorn, A. S. C., \& Gathercole, S. E. (1999). Language-specific knowledge and short-term memory in bilingual and non-bilingual children. Quarterly Journal of Experimental Psychology, 52A, 303 324. doi:10.1080/027249899391089

Thorn, A. S. C., \& Gathercole, S. E. (2001). Language differences in verbal short-term memory do not exclusively originate in the process of subvocal rehearsal. Psychonomic Bulletin \& Review, 8, 357-364. doi:10.3758/BF03196173

Thorn, A. S. C., Gathercole, S. E., \& Frankish, C. R. (2002). Language familiarity effects in short-term memory: The role of output delay and long-term knowledge. Quarterly Journal of Experimental Psychology, 55A, 1363-1383.

Thorn, A. S. C., Gathercole, S. E., \& Frankish, C. R. (2005). Redintegration and the benefits of long-term knowledge in verbal short term memory: An evaluation of Schweickert's (1993) multinomial processing tree model. Cognitive Psychology, 50, 133158. doi:10.1016/j.cogpsych.2004.07.001

Tuner, M. L., \& Engle, R. W. (1989). Is working memory capacity task dependent? Journal of Memory and Language, 28, 127-154. doi:10.1016/0749-596X(89)90040-5
Unsworth, N., \& Engle, R. W. (2006). Simple and complex memory spans and their relation to fluid abilities: Evidence from list-length effects. Journal of Memory and Language, 54, 68-80. doi:10.1016/j.jml.2005.06.003

Vitevitch, M. S., \& Luce, P. A. (2004). A Web-based interface to calculate phonotactic probability for words and nonwords in English. Behavior Research Methods, Instruments, \& Computers, 36, 481-487. doi:10.3758/BF03195594

Wagner, P. K., Torgesen, J. K., \& Rashotte, C. A. (1999). Comprehensive Test of Phonological Processing (CTOPP). Austin, TX: Pro-Ed.

Watkins, O. C., \& Watkins, M. J. (1977). Serial recall and the modality effect: Effects of word frequency. Journal of Experimental Psychology: Human Learning \& Memory, 3, 712-718. doi:10.1037/0278-7393.3.6.712

William, K. T. (1997). Expressive Vocabulary Test. Circle Pines, MN: American Guidance Service.

Windsor, J., Kohnert, K., Lobitz, K. F., \& Pham, G. T. (2010). Crosslanguage nonword repetition by bilingual and monolingual children. American Journal of Speech-Language Pathology, 19, 298310. doi:10.1044/1058-0360(2010/09-0064

Woodcock, R. W., McGrew, K. S., \& Mather, N. (2005). WoodcockJohnson Tests of Cognitive Abilities, Third Edition/Normative Update. Itasca, IL: Riverside Publishing.

Zelazo, P. D., Frye, D., \& Rapus, T. (1996). An age-related dissociation between knowing rules and using them. Cognitive Development, 11, 37-63. doi:10.1016/S0885-2014 (96)90027-1 